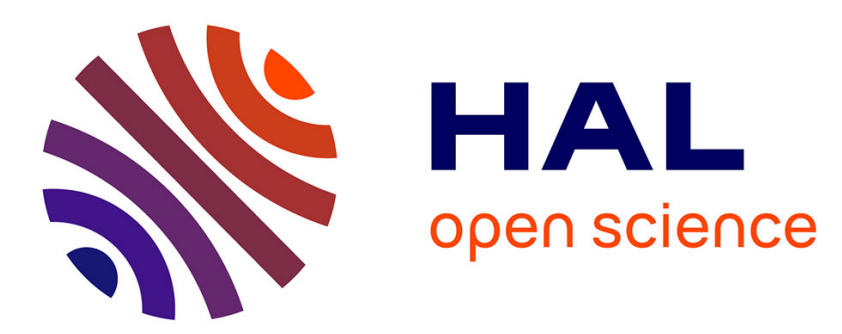

\title{
Terahertz thermometry system to measure temperature in the thickness of a solid polymer
}

\author{
Cyndie Poulin, Meriam Triki, Karim Bousmaki, Alexandre Duhant, Hervé \\ Louche, Bertrand Wattrisse
}

\section{> To cite this version:}

Cyndie Poulin, Meriam Triki, Karim Bousmaki, Alexandre Duhant, Hervé Louche, et al.. Terahertz thermometry system to measure temperature in the thickness of a solid polymer. Quantitative InfraRed Thermography Journal, 2017, 10.1080/17686733.2017.1362791 . hal-01583910

\section{HAL Id: hal-01583910 https://hal.science/hal-01583910}

Submitted on 8 Sep 2017

HAL is a multi-disciplinary open access archive for the deposit and dissemination of scientific research documents, whether they are published or not. The documents may come from teaching and research institutions in France or abroad, or from public or private research centers.
L'archive ouverte pluridisciplinaire HAL, est destinée au dépôt et à la diffusion de documents scientifiques de niveau recherche, publiés ou non, émanant des établissements d'enseignement et de recherche français ou étrangers, des laboratoires publics ou privés. 
Quantitative Infrared Thermography Journal, 2017

https://doi.org/10.1080/17686733.2017.1362791

\title{
Terahertz thermometry system to measure temperature in the thickness of a solid polymer
}

Cyndie Poulin(1), Meriam Triki(1), Karim Bousmaki(2), Alexandre Duhant(1), Hervé Louche $^{(2)}$ and Bertrand Wattrisse ${ }^{(2)}$

- Cyndie Poulin, T-Waves Technologies, Cap Omega, Rd Point B. Franklin, 34960 Montpellier Cedex 2, France, 339724413 81, cyndie.poulin@t-wavestechnologies.com

- $\quad$ Meriam Triki, T-Waves Technologies, Cap Omega, Rd Point B. Franklin, 34960 Montpellier Cedex 2, France, 339724413 81, meriam.triki@t-wavestechnologies.com

- A. Duhant, T-Waves Technologies, Cap Omega, Rd Point B. Franklin, 34960 Montpellier Cedex 2, France, 339724413 81, alexandre.duhant@t-wavestechnologies.com

- Karim Bousmaki, LMGC, Université de Montpellier, CNRS, cc 048, place E. Bataillon, 34095 Montpellier Cedex, France, 04671496 34, a.bousmaki@hotmail.fr

- Corresponding author: Hervé Louche, LMGC, Université de Montpellier, CNRS, cc 048, place E. Bataillon, 34095 Montpellier Cedex, France, 04671496 34, herve.louche@umontpellier.fr

- Bertrand Wattrisse, LMGC, Université de Montpellier, CNRS, cc 048, place E. Bataillon, 34095 Montpellier Cedex, France, 04671447 93, bertrand.wattrisse@umontpellier.fr

The research was conducted under the two affiliations (1) and (2)

\begin{abstract}
This paper deals with thermal attenuation of a transmitted $\mathrm{THz}$ signal $(165 \mathrm{GHz})$ across a POM polymer sample subjected to a thermal gradient in the thickness direction. The paper describes the experimental setup, including a THz sensor, a system to impose thermal loading and an infrared camera used to measure temperature variations at the surface. The thermal dependence of the transmitted THz signal through the sample was studied along a spatial profile. A simple polynomial model, validated through finite element analysis and thermal imaging measurement, was used to estimate temperature variations in the thickness direction. The correspondence between the $2 \mathrm{D}$ transmitted $\mathrm{THz}$ signal and the 3D temperature distribution allowed us to estimate the thermal sensitivity of the absorption coefficient in the $\mathrm{THz}$ range. This study showed that the $\mathrm{THz}$ sensor was sensitive enough to measure $\mathrm{THz}$ signal variations due to small temperature variations. The mean temperature may be determined along the thickness direction once the thermodependence of the transmission and reflection coefficients are known.
\end{abstract}

\section{Keywords}

Terahertz, absorption coefficient, infrared thermography, thermal dependence, POM material 


\section{Introduction}

Infrared thermography temperature measurements are becoming increasingly popular for studying the thermomechanical behaviour of materials during mechanical tests (see [1] and references in this paper). Infrared thermography provides surface measurements. Consequently, thermal fields are only obtained on the sample surface. Due to this experimental limitation, it is sometimes possible to study thin samples in order to ensure that the surface temperatures remain close to the average temperature across the thickness. However, this assumption does not hold for thick samples and/or for high convective heat losses. Moreover, for some materials, e.g. composites, some damage can develop in the thickness during mechanical tests, leading to a possible heterogeneous temperature field in the thickness direction. As XR tomography enables 3D microstructure analysis, a challenge is now to obtain local and volume temperature measurements in heterogeneous situations.

In 2013, Pradère et al. proposed to use the $\mathrm{THz}$ wavelength for temperature measurements at the surface using a thermoreflectance method [2,3] based on a commercial $\mathrm{THz}$ pyrometer. Recently, they demonstrated the possibility to realize thermal tomography [4] with $\mathrm{THz}$ waves using an IR camera. In the present study, we would like to follow this subject of research. As a first step, we consider measurements of thermal transmittance on a planar polymer sample with $\mathrm{THz}$ waves using a $\mathrm{THz}$ sensor developed by T-Waves Technologies [5].

$\mathrm{THz}$ waves refer to electromagnetic waves with a 0.1 to $10 \mathrm{THz}$ frequency range. These wavelengths range from approximately $0.03 \mathrm{~mm}$ to $3 \mathrm{~mm}$. The THz photon energy is around meV. This is very low power, i.e. about 1000 -fold lower than that of transitions between electron levels of atoms, and even lower than the thermal energy at ambient temperature. This energy is insufficient to cause chemical damage to molecules, or to knock particles out of atoms. They are used in non-destructive testing techniques (NDT) since they can penetrate a large number of opaque materials at visible and infrared wavelengths. In this context, $\mathrm{THz}$ imaging has considerable potential for several applications like material characterization of artworks [6] and security applications, such as luggage or passenger inspection. In the plastics industry, THz radiation can be used in multiple applications, such as quality control of welded joints in high density polyethylene (HDPE) [7], determination of water content in plastics and composite materials [8], control of teflon and PVC parts[9]. T-Waves Technologies have been working on polymer applications since this material is used to various extents in numerous components ranging from commodities to high-valued products in the aerospace, aircraft and automotive industries. The electrical properties below a few gigahertz and the optical properties of polymer materials are well known, but there are few reported data on the properties in the far infrared or terahertz ranges. Most nonpolar polymers are semi-transparent in this frequency range [10], which even allows for depth-resolved measurements [11]. Terahertz imaging can address surface-subsurface issues in a reflection configuration and volume issues in a transmission configuration.

In this paper, we report results using terahertz imaging at around $165 \mathrm{GHz}$ for temperature measurement in a polyoxymethylene (POM) semicrystalline polymer. The first Section describes the experimental methodology and setup used to get a steadystate heterogeneous temperature distribution imposed on a parallelepipedic POM 
sample. The two techniques that allow the measurement of $\mathrm{THz}$ radiation and surface temperature through infrared thermography are also presented.

Estimation of the local temperature profile through the thickness is obtained using a parabolic analytical model. This model relies on some hypotheses and experimental temperature measurements at the surface with an infrared camera. The thermal model is presented in Section 3. After a presentation of the main results, a correspondence between the THz amplitude signal and internal temperature is discussed in Section 5.

\section{Experimental methodology}

The objective of the experimental setup was to study possible changes in $\mathrm{THz}$ radiation transmittance through a solid subjected to temperature gradients. The study was conducted on a POM polymer material (Polyacethal-C [12]) that was chosen for its good transparency in the $\mathrm{THz}$ wavelength. The experimental design is presented in Figures 1 and 2. Figure 1 illustrates the parallelepiped POM sample $\left(L_{x} \times L_{y} \times L_{z}=0.045 \mathrm{~m} \times 0.07 \mathrm{~m}\right.$ $\mathrm{x} 0.0116 \mathrm{~m}$ ) in the $\mathrm{THz}$ setup, while Figure 2 shows the device chosen to impose the thermal loading. Two coordinate systems are used in the paper. The first one $R(0, x, y, z)$ originates at point $\mathrm{O}$ located at the intersection of the two mid-width and mid-thickness planes with the upper plane of the sample. Axis z has the same orientation as the $\mathrm{THz}$ beam. The second coordinate system $R^{\prime}\left(O^{\prime}, x^{\prime}, y^{\prime}, z^{\prime}\right)$ is obtained by a translation of half thickness, but with a symmetric $\mathrm{x}$-axis, in order to describe thermal surface measurements. Axis $y$ and $y^{\prime}$ have the same direction and orientation.

The two setups are described in the following sections.

\subsection{THz setup}

Figure 1 illustrates the experimental imaging setup developed by T-Waves Technologies company for acquiring 2D and 3D images of industrial samples [5]. In this study, 2D images were recorded by characterizing the beam intensity attenuation in transmission of an object placed at the focal point of this setup. For 2D imaging, the image was acquired by a point by point setup. The sample is moved in the plane perpendicular to the beam direction. The selected pitch of each axis of the image depends on the desired resolution. As an example, the acquisition time of an image of dimension $50 \mathrm{~mm} \times 80$ $\mathrm{mm}$ and $0.3 \mathrm{~mm}$ pitch on each axis is equal to 10 minutes.

The set up was based on a mW compact source (Radiometer Physics GmbH) which emits at $165.78 \mathrm{GHz}$, corresponding to a $1.80 \mathrm{~mm}$ wavelength in air. The source frequency was generated through a radio frequency synthesizer (Rohde-Schwarz SMB 100A) with a \pm $64 \mathrm{MHz}$ frequency excursion. All used lenses are planoconvex and their focal length about $100 \mathrm{~mm}$. The beam was first collimated through a L1 lens and then focused on the sample through a L2 lens. The beam was then collimated again through a L3 lens and finally focused on the detector through a L4 lens. The beam diameter focused on a sample was about 7,3 $\mathrm{mm}$. The setup was designed to allow the removal of the $\mathrm{THz}$ detection unit in order to measure the surface temperature with an infrared camera. The T-Waves Technologies detector is based on a nano-transistor sensor whose responsivity is about $40 \mathrm{KV} / \mathrm{W}$ at $0.3 \mathrm{THz}$, NEP (noise equivalent power) of $50 \mathrm{pW} / \mathrm{Hz}$ (as formulated in [13]). 


\subsection{Thermal loading setup}

The setup is reported in Figure 2. A hole drilled in the sample enabled circulation of a heat transfer fluid (here water) in order to impose a thermal gradient in the sample, mainly in the radial direction. The fluid temperature was controlled using a thermocryostat with an accuracy of $+/-0.03 \mathrm{~K}$. The fluid was injected with a pump and pipes connected to the sample. The sample was held via two connections linking the pipes and the sample. This sample support solution was chosen in order to impose symmetric boundary conditions.

Five experiments were successively conducted at five different loading states: reference state (room temperature of $\mathrm{T}_{\mathrm{a}}=23^{\circ} \mathrm{C}$ ) and four thermal loadings, corresponding to a water imposed temperature $T_{\text {water }}$ of $30^{\circ} \mathrm{C}, 40^{\circ} \mathrm{C}, 50^{\circ} \mathrm{C}$ and $60^{\circ} \mathrm{C}$.

\subsection{Thermal measurements}

The infrared camera, i.e. an FLIR SC6000 with a NETD (noise equivalent temperature difference) thermal resolution of $20 \mathrm{mK}$, was focused on the entire front face. This surface was precoated with high emissivity paint in order to obtain an emissivity factor close to the blackbody emissivity used in the camera calibration model. The infrared camera also focused on a small reference sample, with the same characteristics as the studied sample (material, thickness and coating conditions), in the upper right corner (see Figure 2). It gave the reference thermal state under the same thermal boundary conditions. The thermal field measured with the infrared camera at point $M_{i}$, located in the front surface at pixel coordinate $x_{i}{ }^{\prime}$ and $y_{i}{ }^{\prime}$, is noted $T_{\text {surf }}\left(x_{i}{ }^{\prime}, y_{i}{ }^{\prime}\right)$.

An example of such thermal field $T_{\text {surf }}$ is given in Figure $3(a)$ for the last thermal loading $\left(60{ }^{\circ} \mathrm{C}\right)$. The thermal profile on the sample front surface, in the radial direction $\mathrm{AD}$ indicated by the red line in Figure 3(a), is plotted in Figure 3(b). The first figure shows a strong temperature gradient in the radial direction $\left(y^{\prime}\right)$ and a weak variation in the axial direction $\left(x^{\prime}\right)$. Quantitative temperature values are given in Figure 3(b). The temperature was maximum at the surface located just on the hole axis (around position $y^{\prime}=0.034 \mathrm{~m}$ ), with a thermal variation close to $20^{\circ} \mathrm{C}$ in the radial direction.

\subsection{THz measurements}

Only one part (area ABCD Figure 2) was scanned by the THz beam. This beam was emitted by the THz source and it entered the sample through the back face. The $\mathrm{THz}$ sensor finally measured the intensity of the transmitted beam through the sample. The transmitted $\mathrm{THz}$ radiation was acquired only during the thermal steady state. This state was obtained after waiting around 1 hour for a given imposed heat fluid temperature. We have verified on half painted samples that the black paint coating used for thermal measurements slightly diminishes the $\mathrm{THz}$ attenuation and that the thermal sensitivity of the attenuation coefficient is not affected by the paint.

The THz image (area ABCD indicated in Figure 2) plotted in Figure 4(a) shows the intensity of the transmitted $\mathrm{THz}$ beam, denoted $I_{T}$, through the sample, for a thermal loading corresponding to a water imposed temperature $T_{\text {water }}$ of $60^{\circ} \mathrm{C}$. The blue part, with very low transmitted radiation, corresponds to water circulating in the hole, which was opaque to $\mathrm{THz}$ radiation. Then, as given in the radial profile along the $\mathrm{AD}$ line plotted in Figure 2(b), the transmitted $\mathrm{THz}$ increased as the distance from the hole increased and the temperature decreased. 


\section{Thermal modelling}

The experimental setup presented in the previous section allowed us to impose thermal gradients mainly oriented on the $y$-axis of the specimen. Nevertheless, thermal gradients may develop on the $x$ and $z$ axes due to the thermal flux coming from the water-filled hole and to heat exchanges with the surroundings. The aim of this section is to propose a simple, analytical, thermal model to obtain a precise description of the thermal gradients in the sample thickness using only surface thermal measurements. It is thus possible to assess the inner temperature distribution using the surface temperature obtained by infrared thermography.

The analytical model was validated on a thermal finite element simulation corresponding to the setup configuration. The 3D temperature field is noted $T=T(x, y, z)$, where $x, y$ and $z$ are the spatial coordinate in the $R$ coordinate system. Figure 5(a) shows the geometric description of the specimen. Using symmetry considerations (3 planar symmetry corresponding to the 3 reference planes), we restricted the thermal model to $1 / 8$ of the geometry. The specimen was a perfect rectangular parallelepiped with a circular hole drilled on its longitudinal axis. The geometry was assumed to be perfectly known, with the dimensions in the $x, y$ and $z$ directions being $L_{x}=0.045 \mathrm{~m}, L_{y}=0.07 \mathrm{~m}$ and $L_{z}=0.01161 \mathrm{~m}$, hole radius $R=0.003 \mathrm{~m}$. Natural convection and radiation exchanges were imposed, as boundary conditions, on the outer surfaces of the sample:

$$
-k \frac{\partial T}{\partial \vec{n}} \cdot \vec{n}=h_{\text {air }}\left(T-T_{a}\right)+\varepsilon_{\text {surface }} \sigma\left(T^{4}-T_{a}^{4}\right)
$$

where $k$ is the material thermal conductivity $\left(\mathrm{W} \cdot \mathrm{m}^{-1} \mathrm{~K}^{-1}\right), h_{\text {air }}$ the natural convection coefficient with the surrounding air $\left(\mathrm{W} \cdot \mathrm{m}^{-2} \mathrm{~K}^{-1}\right), T_{\mathrm{a}}$ the ambient temperature, $\varepsilon_{\text {surface }}$ the surface emissivity, $\sigma=5.6710^{-8} \mathrm{Wm}^{-2} \mathrm{~K}^{-4}$ the Stefan-Boltzmann constant, and with $\vec{n}$ being the vector corresponding to the surface outer normal. Vector $\vec{n}$ is equal respectively to $\pm \vec{x}, \pm \vec{y}$ or $\pm \vec{z}$ for the left/right, top/down and front/rear faces of the specimen.

Heat exchanges between the water and the specimen on the hole surface were assumed to correspond to forced convection with a convection coefficient $h_{\text {water, }}$ with the water being at temperature $T_{\text {water: }}$

$$
-k \frac{\partial T}{\partial \vec{n}} \cdot \vec{n}=h_{\text {water }}\left(T-T_{\text {water }}\right)
$$

The simulations were performed on Comsol MultiPhysics using quadratic tetrahedron elements (with a characteristic mesh size of $0.0007 \mathrm{~m}$ ) and steady-state analysis. The parameters used in the simulation were consistent with the experimentally investigated situation, as given in Table 1.

The values in Table 1 were identified in an experiment performed on a POM sample. The protocol used to identify these parameters will be detailed later. Figure 5(a) illustrates the obtained temperature distribution. As expected, the temperature gradients were mainly oriented along the $y$ direction from the hole to the sample side. The temperature increase reached around $25{ }^{\circ} \mathrm{C}$ on the sample surface when the ambient temperature was $23{ }^{\circ} \mathrm{C}$ and the temperature of the water circulating in the hole was $60{ }^{\circ} \mathrm{C}$. This numerical model also allowed us to determine the temperature within the sample (see Figure 5(b) illustrating the temperature variations along the sample thickness at point 
E). This profile shows that the temperature distribution has a parabolic shape with an horizontal tangent in the middle of the sample (stemming from the computation symmetry conditions). In the following, we propose to use a fin assumption to estimate the temperature profile along the specimen width. Based on this hypothesis, the temperature profile should be parabolic and maximum in the middle of the sample. If the symmetry plane corresponds to $z=0$, the parabola describing to the $z$-variations of the temperature at point $M_{i}\left(x_{i}, y_{i}, L_{z} / 2\right)$ should read:

$$
T\left(x_{i}, y_{i}, z\right)=\alpha_{i}-\beta_{i}\left(z^{2}-L_{z}^{2} / 4\right)
$$

with parameters $\alpha_{i}$ and $\beta_{i}$ being determined from measurable surface thermal data. When formulating a thermal balance at point $M_{i}$, and based on the fact that the normal to the surface at this point is $\vec{n}=\vec{z}$, we get:

$$
\begin{aligned}
\alpha_{i} & =T\left(x_{i}, y_{i}, L_{z} / 2\right) \\
\beta_{i} & =\left.\frac{-1}{L_{z}} \frac{\partial T}{\partial z}\right|_{x_{i}, y_{i}, L_{z} / 2}
\end{aligned}
$$

Using Equations (4) and (5) in Equation (1), we obtain:

$$
\beta_{i}=\frac{1}{k L_{z}}\left(h_{\text {air }}\left(\alpha_{i}-T_{a}\right)+\varepsilon_{\text {surface }} \sigma\left(\alpha_{i}^{4}-T_{a}^{4}\right)\right)
$$

Equations (4) and (6) show that, as expected, the parabola coefficients could be estimated using only surface thermal measurements provided that the heat exchange coefficients $\left(k, h_{\text {air }}, \varepsilon_{\text {surface }}\right)$ are known. In Figure 5(b), we illustrate the temperature profile along the $z^{\prime}$-axis at point $M_{i}=E$ associated with Equation (3) and using the coefficients given in Table 1 . Because of the symmetry, the profile is limited to half thickness and we chose to present the thickness evolution in the $R^{\prime}$ coordinate system. Point $E$ is the closest to the hole to be investigated. Figure 5(b) shows that the parabolic model was in very good agreement with the $3 \mathrm{D}$ temperature variation pattern (around $0.04 \mathrm{~K}$ in the mid position $\mathrm{z}=0\left(z^{\prime}=L_{z} / 2\right)$ and less than $0.01 \mathrm{~K}$ discrepancy for the mean value in the thickness direction).

In a real experiment, the heat exchange coefficients have to be determined. The emissivity of the samples coated with black paint was very high and typically around 0.95 [1]. The ambient temperature $T_{\mathrm{a}}$ was measured with a thermocouple before the test on the reference sample, and it varied between $23^{\circ} \mathrm{C}$ and $27{ }^{\circ} \mathrm{C}$ depending on the test. The material thermal conductivity $k$ was measured at $0.35 \pm 0.15 \mathrm{Wm}^{-1} \mathrm{~K}^{-1}$ using the hot disk technique (ISO 22007-2 :2008 standard).

The heat exchange coefficient with the surrounding air depended on the experimental conditions. This coefficient was estimated on the side surface of the specimen. When formulating a thermal balance on this surface and considering that the outer normal on this boundary is $\vec{n}=\vec{x}$, we can deduce that the flux quantity is:

$$
\Phi=\left(-\left.k \frac{\partial T}{\partial x}\right|_{L_{x} / 2, y_{i}, L_{z} / 2}-\varepsilon_{\text {surface }} \sigma\left(T\left(L_{x} / 2, y_{i}, L_{z} / 2\right)^{4}-T_{a}^{4}\right)\right)
$$

and should vary linearly with respect to:

$$
T\left(L_{x} / 2, y_{i}, L_{z} / 2\right)-T_{a}
$$


with the slope being $h_{\text {air }}$. The quantity $\Phi$ is totally determined from surface temperatures $\left(T\left(x_{i}, y_{i}, L_{z} / 2\right)\right)$ and ambient temperature $\left(T_{a}\right)$ once the surface emissivity $\left(\varepsilon_{\text {surface }}\right)$ and the thermal conductivity $(k)$ are known. In equation (7), quantities $T\left(L_{x} / 2, y_{i}, L_{z} / 2\right)$ and $\frac{\partial T}{\partial x}\left(L_{x} / 2, y_{i}, L_{z} / 2\right)$ are deduced from the thermal images recorded by the infrared camera that gives $\mathrm{T}\left(x_{i}, y_{i}, L_{z} / 2\right)$ for all the points $\left(x_{i}, y_{i}\right)$ on the sample surface characterized by $\mathrm{z}=\mathrm{L}_{\mathrm{z}} / 2$.

Figure 6 illustrates the correlation between these two quantities using the finite element simulation data. The identified convection exchange coefficient was $8.3 \mathrm{Wm}^{-2} \mathrm{~K}^{-1}$, which was the coefficient used for the simulation. This demonstrated the efficiency of the proposed methodology for identifying the heat exchange coefficient. This method will be used in the Results section. Imperfections with respect to knowledge on the other parameters will naturally generate errors in the identified coefficient. Let us finally mention that coefficient $h_{\text {water }}$ mainly governed heat transfer between the warm water and the specimen, and consequently, it controlled the overall warming of the sample. It did not markedly influence the shape of the temperature profile along the sample thickness. Consequently, this coefficient was not identified in the experimental tests.

\section{Results}

The method used to estimate the convection exchange coefficient described in the previous part was then applied to the four loading states (four water temperatures, ranging from $30{ }^{\circ} \mathrm{C}$ to $60^{\circ} \mathrm{C}$ ). These coefficients, which only slightly increased with the water temperature, are reported in Figure 7. The estimation accuracy was better when the loading temperature was increasing because the temperature variations were greater. However, despite the poor accuracy for the first two loading states $\left(30^{\circ} \mathrm{C}\right.$ and $40{ }^{\circ} \mathrm{C}$ ), the estimated values were in line with classical natural convection coefficients. These values were thus used to estimate the temperature distribution in the thickness direction.

The different thermal profiles along the AD line measured during the reference state (ambient temperature) and during the four steady loading states are given in Figure $8(a)$. The thermal gradients increased in the radial direction when the imposed water temperatures increased. The temperature variation profiles ( $\mathrm{T}-\mathrm{T}_{\text {surf }}$ ) along the thickness direction at point $\mathrm{E}$ for the four loading states, estimated with the parabolic thermal model and with the temperature measurement at point E, are plotted in Figure 8(b). The term $\mathrm{T}_{\text {surf }}$ represents the surface temperature measured at point $\mathrm{E}$. These plots show the temperature variation amplitude in the thickness direction, which reached $1.5^{\circ} \mathrm{C}$ for the maximum loading state at $60^{\circ} \mathrm{C}$.

The corresponding transmitted THz profiles along the AD line for the reference and the four loading states are plotted in Figure 9. As previously observed in Figure 4, the intensity decreased as the temperature increased.

\section{Discussion}

The thermal and THz images were recorded at different times. As the recordings were performed in steady state, no temporal matching was performed. The spatial matching 
procedure consists of applying rotation, dilatation and translation to the thermal image in order to make the 3 corners of the specimen coincide on the $\mathrm{THz}$ image and on the transformed IR image. Once the coinciding IR and $\mathrm{THz}$ images are obtained, the measurements can be compared at specific points for a given imposed water temperature. Hereafter, only AE profiles were studied (see Figure 2).

The transmission coefficient $\Gamma_{T H z}$ across the sample thickness was calculated for each discrete point $M_{i}\left(x_{i}, y_{i}\right)$ located at position $\left(x_{i}, y_{i}\right)$ on the front surface using the following ratio:

$$
\Gamma_{T H z}\left(x_{i}, y_{i}\right)=\frac{I_{T}\left(x_{i}, y_{i}\right)}{I_{0}}
$$

where $I_{0}$ is the THz radiation emitted by the source and $I_{T}$ is the one transmitted across the thickness. Figure 10 pools the data obtained for all imposed water temperatures $\left(T_{\text {water }}=\mathrm{T}_{\mathrm{a}}, 30{ }^{\circ} \mathrm{C}, 40{ }^{\circ} \mathrm{C}, 50{ }^{\circ} \mathrm{C}\right.$ and $\left.60{ }^{\circ} \mathrm{C}\right)$ for all points $M_{i}$ located on the AE profile. Although, they were obtained in different tests (associated with different experimental conditions), the responses of all points for all water temperatures were plotted on a master curve associated with the thermo-dependence of the $\mathrm{THz}$ absorption and/or reflection coefficients.

Figure 10 corresponds to the "raw" experimental results showing a temperaturedependence of the THz transmission through the sample. Due to the presence of thermal gradients along the sample depth, the interpretation of this figure is not straightforward: for a given material and a given $\mathrm{THz}$ source frequency, it depends, on every condition that modifies the thermal conditions in which the experiment is performed (sample thickness and heat exchanges, ...). Since we are using a monochromatic THz source, the frequency dependence of the absorption and transmission coefficients will be omitted. Hereafter, we propose an interpretation framework to characterize the temperature dependence of the absorption coefficient using these data. A simplified phenomenological model, proposed for $\mathrm{THz}$ radiation propagation, is illustrated in Figure 11. At ambient temperature and in the $\mathrm{THz}$ range, air located between the $\mathrm{THz}$ source and the sample and between the sample and the $\mathrm{THz}$ sensor is considered as a perfectly transparent medium with a refraction index $n$ equal to 1 . The setup configuration ensures that the incoming $\mathrm{THz}$ radiation emitted by the source, denoted $I_{0}$, is perpendicular to the surface. As it encounters the first interface, part of this radiation is reflected (let $R$ be the reflection coefficient) and the complementary part is absorbed or transmitted in the media (let $n$ be its refraction index and $\alpha$ the absorption coefficient along the radiation path). The refraction index gradient is assumed to follow the thermal gradient existing in the thickness direction $(z)$. Consequently, as the radiation arrives perpendicular to the surface, its propagation remains straight. Along the radiation path (here in the $z$-direction), the radiation is absorbed according to the Beer-Lambert law:

$$
d I=-I(z) \alpha(z) d z
$$

where $d I$ is the intensity attenuation due to radiation absorption between $z$ and $z+d z$. Note that the absorption coefficient $\alpha(z)$ may depend on the position $z$ along the sample width.

In order to determine the dependence of absorption and reflection coefficients on the POM sample with the temperature, we used a THz spectrometer based on Time Domain 
Spectroscopy (TDS) whose protocol is described in details in [14, 15]. In transmission configuration, this spectrometer allows measurement of absorption coefficient and refractive index which is related to the reflection coefficient. We placed the sample inside the spectrometer and we increased its temperature by the same water circulation system as described in section 2.2. The measurements include the optical response of both sample's interfaces. We report in Table 2 the obtained optical parameters at 165 $\mathrm{GHz}$ for a water temperature at ambient temperature and $60^{\circ} \mathrm{C}$.

We observed a slight variation on refractive index (about $1 \%$ ) and a significant variation on absorption coefficient (about tens of percentage depending on the position in the sample). Using an analytical model and the optical parameters reported in Table 1, we calculated the reflection coefficient at $165 \mathrm{GHz}$ and for these 2 temperatures. It is about $6.5 \%$ at ambient temperature and $5.5 \%$ at $60{ }^{\circ} \mathrm{C}$ temperature for one interface.

The absorption coefficient increased with increasing temperature, as already observed in other research work [14]. The observed decrease in intensity was then due mainly to the increased absorption with increasing temperature.

To simulate the transmitted intensity, we consider Equations (11) and (12) which shows the linear dependence of absorption coefficient $\alpha$ with temperature:

$$
\begin{gathered}
R=a_{R} \\
\alpha(T)=a_{\alpha}+b_{\alpha}\left(T-T_{0}\right)
\end{gathered}
$$

The linear assumption of eq (12) corresponds to a first order Taylor expansion of the absorption with respect to the temperature. This assumption is justified by the fact that the reflection coefficient does not depend on temperature in the investigated temperature range and the overall transmission coefficient varies with temperature, as can be seen in Figure 10. In Equations (11) and (12), $T_{0}$ was arbitrarily chosen to be equal to $300 \mathrm{~K}$, and the coefficients $a_{R}, a_{\alpha}$ and $b_{\alpha}$ have to be determined. The reflection coefficient $a_{R}$ at $T_{0}$ was set to the average of the values calculated at $60{ }^{\circ} \mathrm{C}$ and at room temperature (i.e. $a_{R}=0.06$ ). The two other parameters in Equation (12) are estimated using the comparison between $\mathrm{THz}$ and thermal measurements.

Under the aforementioned hypotheses, the transmitted radiation $I_{T}$ can be formulated as follows:

$$
I_{T}\left(x_{i}, y_{i}\right)=I_{0}\left(1-R\left(T_{e}\left(x_{i}, y_{i}\right)\right)\right) e^{-\int_{z=-L_{z} / 2}^{L_{z} / 2} \alpha\left(T\left(x_{i}, y_{i}, z\right)\right) d z}\left(1-R\left(T_{l}\left(x_{i}, y_{i}\right)\right)\right)
$$

In this relation, $T_{\mathrm{e}}\left(x_{i}, y_{i}\right)=\mathrm{T}\left(x_{i}, y_{i},-L_{z} / 2\right)$ is the temperature of the point where the $\mathrm{THz}$ radiation enters the sample and $T_{l}=\left(x_{i}, y_{i}\right)=\mathrm{T}\left(x_{i}, y_{i}, L_{z} / 2\right)$ the temperature of the point where it leaves the sample.

In equation (13), the temperature dependence of $\alpha$ is translated into $z$ dependence due to the thermal gradient along the sample width. As the temperature profile is symmetric with respect to the plane $z=0$, we have $T_{\mathrm{e}}\left(x_{i}, y_{i}\right)=T_{1}\left(x_{i}, y_{i}\right)=\alpha_{i}$ and equation (13) becomes:

$$
I_{T}\left(x_{i}, y_{i}\right)=I_{0}\left(1-a_{R}\right)^{2} e^{-\int_{z=-L_{Z} / 2}^{L_{z} / 2}\left(a_{\alpha}+b_{\alpha}\left(\alpha_{i}-\beta_{i}\left(z^{2}-L_{Z}^{2} / 4\right)-T_{0}\right)\right) d z}
$$


where $a_{\alpha}$ and $b_{\alpha}$ are the unknown parameters.

The THz transmission coefficient $\Gamma_{T H z}$ defined by equation (9) was measured by the THz sensor on the whole sample surface. Hereafter, we restricted our study to the points $M_{i}$ located on the AE longitudinal profile. Using Equations (9) and (14), we applied a nonlinear least-square algorithm to minimize the discrepancy between the measured logarithm of the $\mathrm{THz}$ transmission coefficient and the model. The minimized cost function reads:

$$
\begin{aligned}
& F\left(a_{\alpha}, b_{\alpha}\right)=\sum_{i}\left(\log \left(\Gamma_{T H Z}\right)-\left(2 \log \left(\left(1-a_{R}\right)\right)-\int_{z=-L_{z} / 2}^{L_{z} / 2}\left(a_{\alpha}+b_{\alpha}\left(\alpha_{i}-\beta_{i}\left(z^{2}-L_{z}^{2} / 4\right)-\right.\right.\right.\right. \\
& \left.\left.\left.\left.T_{0}\right)\right) d z\right)\right)^{2}
\end{aligned}
$$

By minimizing this cost function for all points $M_{\mathrm{i}}$ and for all imposed water temperatures, we get the optimal parameters $a_{\alpha}^{o p t}$ and $b_{\alpha}^{\text {opt }}$ describing the thermal dependence of the absorption coefficient. This minimization was performed using a trust-region minimization algorithm. The evolution of the transmission coefficient in the radial direction $y^{\prime}$ is plotted in Figure 12 for all applied water temperatures. The difference between the "measurement" (dashed line) and the "model" (continuous line) is very small and the model enables us to capture variations in the $\mathrm{THz}$ transmission coefficient with a very limited number of parameters.

Figure 13 shows the variations in the absorption coefficient $\alpha$ with temperature according to Equation (12) and using the $a_{R}, a_{\alpha}^{o p t}$ and $b_{\alpha}^{o p t}$ parameters. Coefficient $\alpha$ significantly increased with temperature (around 100\% increase for $45{ }^{\circ} \mathrm{C}$ temperature amplitude between $295 \mathrm{~K}$ and $340 \mathrm{~K}$ ). This variation in $\alpha$ with $T$ was consistent with earlier studies performed on POM material but with different configurations (frequency, thickness, etc.) [14], and they are also consistent with the ones we have measured using TDS (see Table 2).

The mean temperature can be determined along the $\mathrm{THz}$ direction once the thermodependence of the transmission coefficients are known and using the constant reflection coefficient. In the present case, as the specimen was normal to the $\mathrm{THz}$ beam, we could obtain the mean temperature along the thickness direction (using the following expression deduced from Equations (11-13):

$$
\bar{T}=T_{0}-\frac{a_{\alpha}}{b_{\alpha}}-\frac{1}{L_{z} b_{\alpha}} \ln \left(\frac{I_{T}}{I_{0}\left(1-a_{R}\right)^{2}}\right)
$$

\section{Conclusion}

An experimental setup was proposed to impose a controlled thermal gradient in the volume of a parallelepipedic polymer sample in the steady-state regime. A THz signal transmitted through this sample was imaged then for different points in the sample along a profile, an infrared camera measured the surface temperatures and the temperature in the thickness direction was obtained via an analytical model. A finite element analysis allowed us to validate the underlying hypotheses of this model as well as the identification procedure used to determine the coefficient values in the model boundary conditions. The analysis of $\mathrm{THz}$ and thermal measurements obtained on the 
sample profile, combined with the thermal model, enabled us to identify the thermodependence of the $\mathrm{THz}$ absorption coefficient.

The present study showed that the $\mathrm{THz}$ sensor was sensitive enough to measure $\mathrm{THz}$ signal variations due to small temperature variations. Other studies are under way for other polymers. The present experimental device has a rotational stage on which the sample is placed which allows acquisition of a 2D image for each angle step, and in the future, we hope to be able to obtain 3D thermal measurements by $\mathrm{THz}$ tomography for a given material based on knowledge of the thermal dependence of the reflection and absorption coefficients.

For a given material, the thermal-dependency of these coefficients have to be determined only once, for example, using the proposed methodology. Afterwards, it is no longer necessary to know the temperature distribution within the sample: the sole interpretation of $\mathrm{THz}$ measurement (via a tomographic reconstruction of the $\mathrm{THz}$ absorption coefficient) should be sufficient to reconstruct internal temperature distributions. Furthermore it is also possible to reach thickness-averaged temperatures once the thermal dependency of the absorption coefficient is known without any a priori on the temperature profile.

\section{Disclosure statement}

No potential conflict of interest is reported by the authors.

\section{References:}

[1] Chrysochoos A. Infrared thermography applied to the analysis of material behavior: a brief overview. QIRT Journal. 2012;9:193-208.

[2] Pradere C, Caumes JP, BenKhemis S, Pernot G, Palomo E, Dilhaire S, Batsale JC. Thermoreflectance temperature measurement with millimeter wave. Review of Scientific Instruments. 2014,85:064904-1-064904-4.

[3] Pradère C, Caumes JP, Benkhemis S, Palomo E, Dilhaire S, Balageas D, Batsale JC, Transient thermal tomography for temperature measurement by using terahertz photoreflectometry. PhotoMechanics Conference. Montpellier. May 27-30. 2013;179182

[4] Romano M, Sommier, Batsale A J.-C, Pradere C, 3D transient temperature measurement in homogeneous solid material with THz waves. SPIE Photonics Europe; 04/2016

[5] Triki M, Duhant A, Poulin C, Moulin B, Archier C, Antonini T, Teppe F, Knap W. Realtime non-destructive imaging with $\mathrm{THz}$ waves. IEEE Conference Publications. DOI: 10.1109/MIKON.2016.7492135. 21st International Conference on Microwave, Radar and Wireless Communications (MIKON), May 9-11. 2016;1-3.

[6] Fukunaga K, Picollo M. Terahertz spectroscopy applied to the analysis of artists materials. Applied Physics A: Materials Science \& Processing. 2010;100(Issue 3) 591-597.

[7] Wietzke S, Jordens C, Krumbholz N, Baudrit B, Bastian M, Koch M. Tera-hertz imaging: a new non-destructive technique for the quality control of plastic weld joints. J. European Optical Society Rapid Publication 2. 2007;07013-1-07013-5. 
[8] Jordens C, Wietzke S, Scheller M, Koch M, Investigation of the water absorption in polyamide and wood plastic composite by terahertz time-domain spectroscopy. Polymer Testing. 2010;29(2)209-215.

[9] Beckmann J, Richter H, Zscherpel U, Ewert U, Weinzierl J, Schmidt LP, Rutz F, Koch M, Richter H, Hubers HW. Imaging capability of Terahertz and millimeter-wave instrumentations for NDT of polymer materials. European Conference on Non Destructive Testing (ECNDT2006). 2006.

[10] Jin Y, Kim G, Jeon S, Terahertz dielectric properties of polymers. Journal of the Korean Physical Society. 2006;49(2)513-517.

[11] Obradovic J, Collins JHP, Hirsch O, Mantle MD, Johns ML, Gladden LF. The use of $\mathrm{THz}$ time-domain reflection measurements to investigate solvent diffusion in polymers. Polymer. 2007;48(12)3494-3503.

[12] POM-C supplier: http://www.lcm-metaux.com

[13] Schuster F, Coquillat D, Videlier H, Sakowicz M, Teppe F, Dussopt L, Giffard B, Skotnicki T, Knap W. Broadband terahertz imaging with highly sensitive silicon CMOS detectors. Optics Express. 2011;19(8)7827-7832.

[14] Wietzke S, Jansen C, Jung T, Reuter M, Baudrit B, Bastian M, Chatterjee S, Koch M. Terahertz time-domain spectroscopy as a tool to monitor the glass transition in polymers. Optics Express. 2009;17(21)19006-19014.

[15] Jin YS, Kim GJ, Jeon SG. Terahertz Dielectric Properties of Polymers. Journal of the Korean Physical Society. 2006; 49(2)513-517. 


\section{Tables with captions}

\begin{tabular}{|c|c|c|c|c|c|}
\hline $\begin{array}{c}k \\
\left(\mathrm{Wm}^{-1} \mathrm{~K}^{-1}\right)\end{array}$ & $\begin{array}{c}h_{\text {air }} \\
\left(\mathrm{W} \mathrm{m}^{-2} \mathrm{~K}^{-1}\right)\end{array}$ & $\begin{array}{c}h_{\text {water }} \\
\left(\mathrm{Wm}^{-2} \mathrm{~K}^{-1}\right)\end{array}$ & $\begin{array}{c}T_{\mathrm{a}} \\
\left({ }^{\circ} \mathrm{C}\right)\end{array}$ & $\begin{array}{c}T_{\text {water }} \\
\left({ }^{\circ} \mathrm{C}\right)\end{array}$ & $\varepsilon_{\text {surface }}$ \\
\hline 0.35 & 8.3 & 200 & 23 & 60 & 0.95 \\
\hline
\end{tabular}

Table 1: Parameter values used in the thermal finite element model.

\begin{tabular}{|l|c|c|}
\hline & Ambient temperature & $60{ }^{\circ} \mathrm{C}$ temperature \\
\hline Refractive index R & 1.686 & 1.613 \\
\hline Absorption coefficient $\left(\mathrm{cm}^{-1}\right)$ & 1.001 & 1.657 \\
\hline Measured transmittance by TDS (\%) & 26.28 & 12.23 \\
\hline
\end{tabular}

Table 2. Optical parameters determined by TDS at $165 \mathrm{GHz}$ 


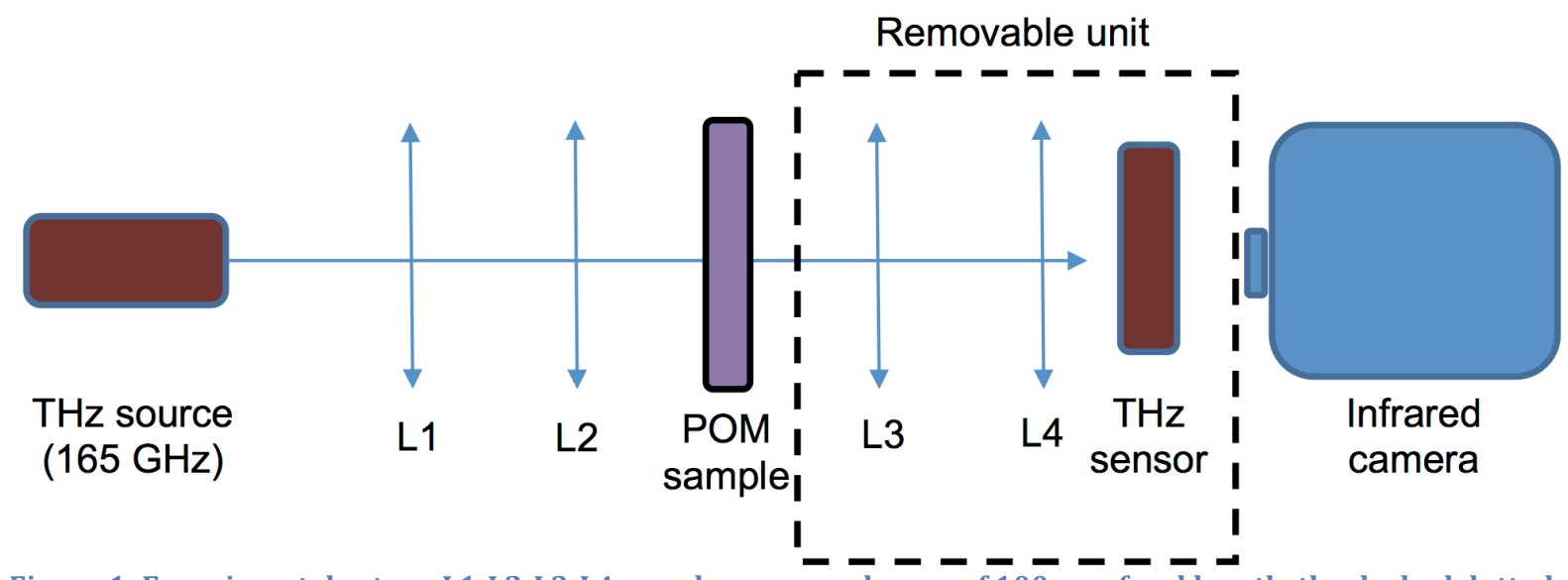

Figure 1: Experimental set up, L1-L2-L3-L4 are planoconvex lenses of $100 \mathrm{~mm}$ focal length, the dashed dotted line indicates a removable $\mathrm{THz}$ detection unit allowing temperature field measurement at the surface with an infrared camera.

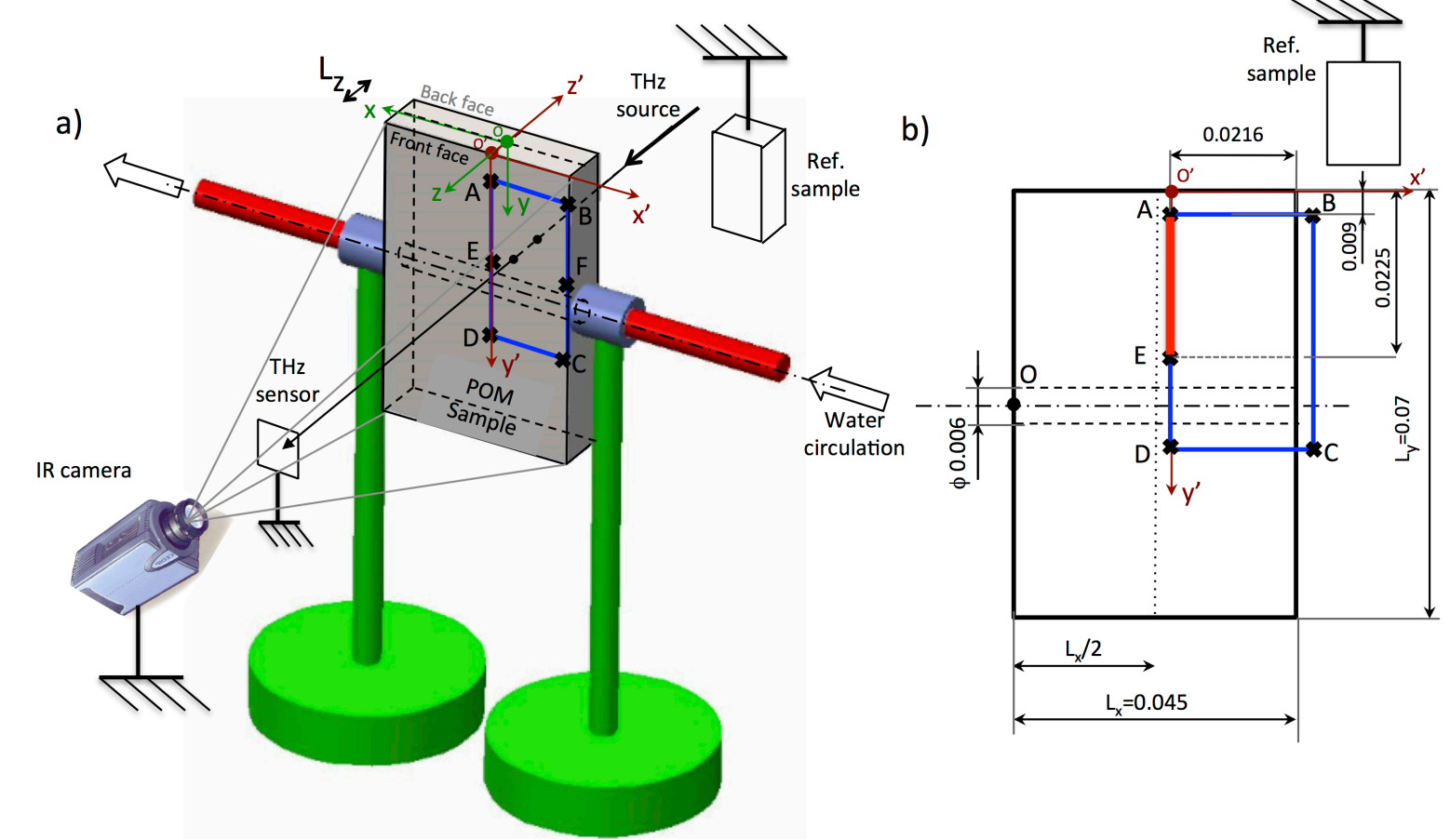

Figure 2: a) Scheme of the experimental setup with the two pipes (in red) connected to a hole (diameter $\phi=0,006 \mathrm{~m})$, through which hot water circulated. b) Scheme of the sample front face $\left(L_{x} \times L_{y} \times L_{z}=0.07 \times 0.045 \times\right.$ $0.012 \mathrm{~m}^{3}$ ). All dimensions are given in $\mathrm{m}$. 
a)

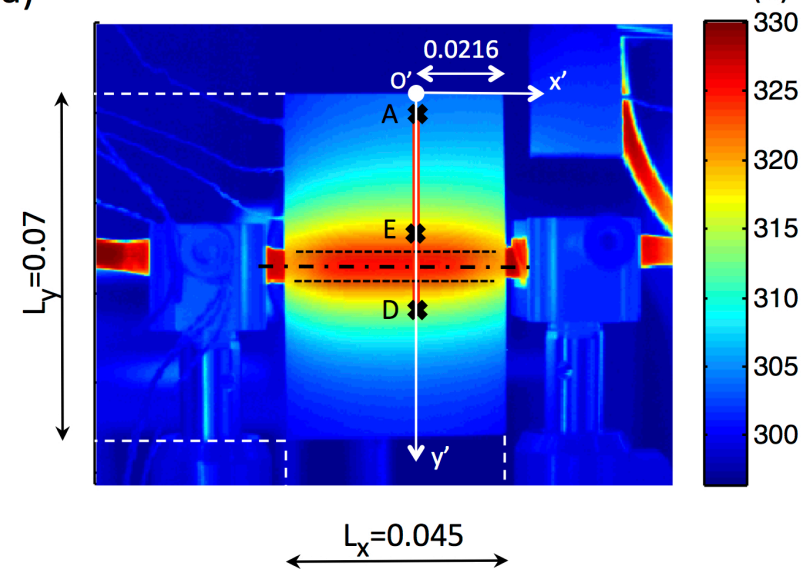

b)

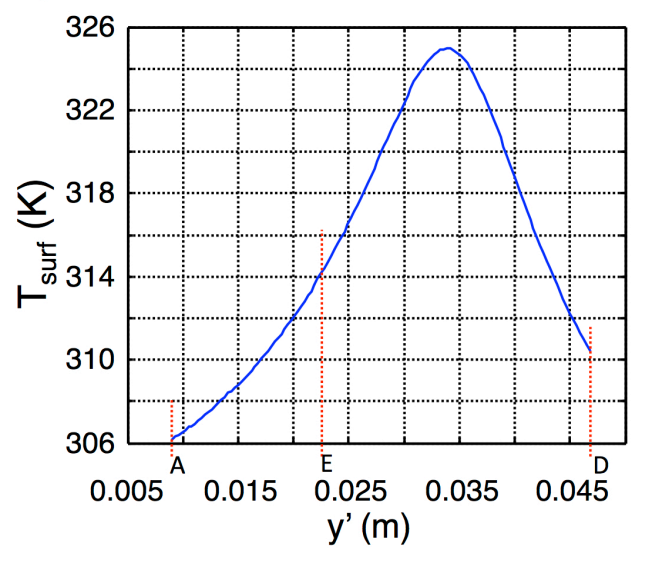

Figure 3 : a) Example of a thermal image $T_{\text {surf }}$ recorded for a thermal loading of $T_{\text {water }}=60{ }^{\circ} \mathrm{C}$ imposed by the heat transfer fluid, the colorbar indicates the temperature in Kelvin (K). b) Thermal profile (in $\mathrm{K}$ ) measured at the surface, in the radial direction AD indicated in Figures 2(b) and 3(a). The position (m) is given in the $y^{\prime}$ axis system plotted in Figure 2.

a)

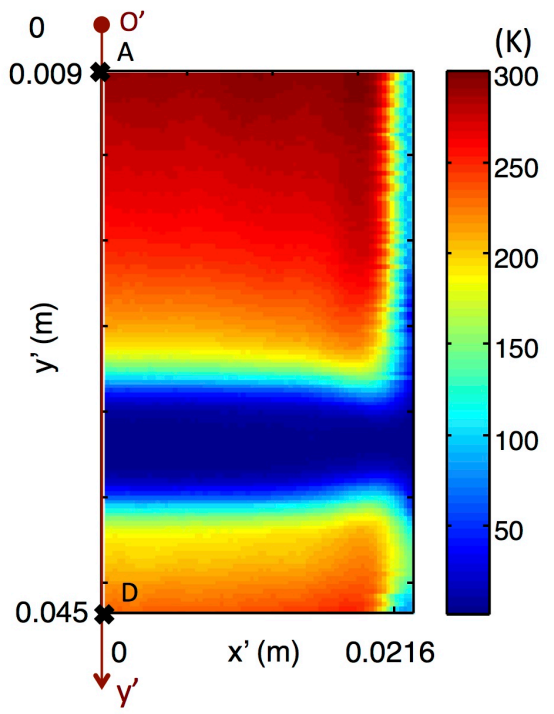

b)

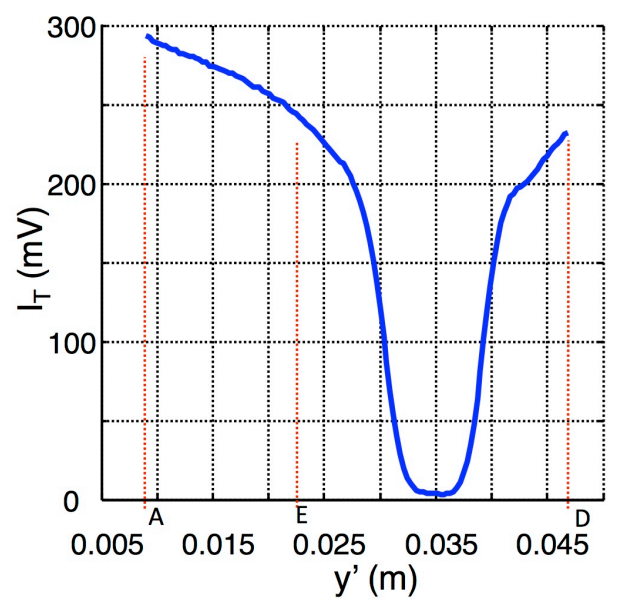

Figure 4 : a) THz image showing the intensity (in $\mathrm{mV}$ ) of the transmitted THz beam measured by the THz sensor (area ABCD indicated in Figure 2) for a thermal loading corresponding to a water imposed temperature $T_{\text {water }}=60^{\circ} \mathrm{C}$. b) THz profile measured in the radial direction $\mathrm{AD}$ indicated in Figures $2(\mathrm{~b})$ and $3(a)$. The position (in $\mathrm{m}$ ) is given in the $y^{\prime}$ axis system plotted in Figure 2. 


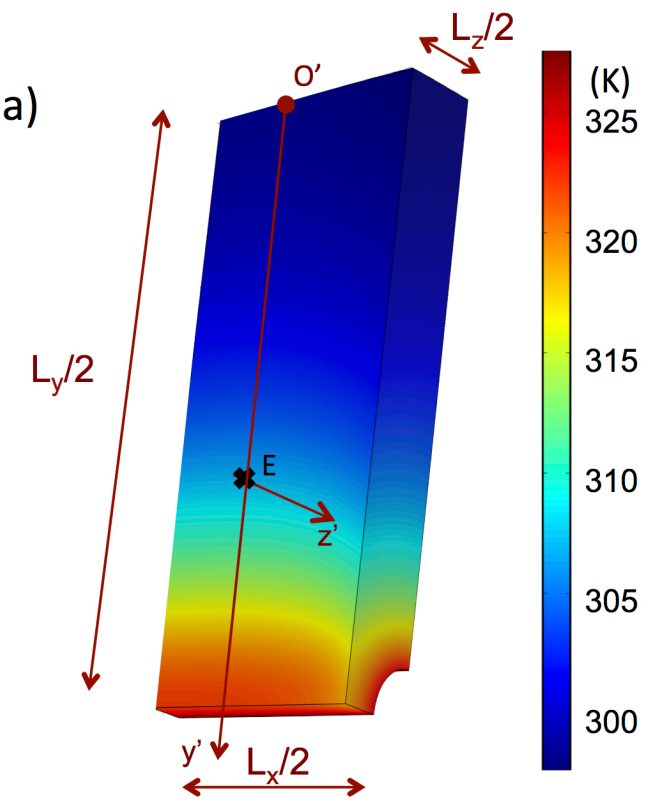

b)

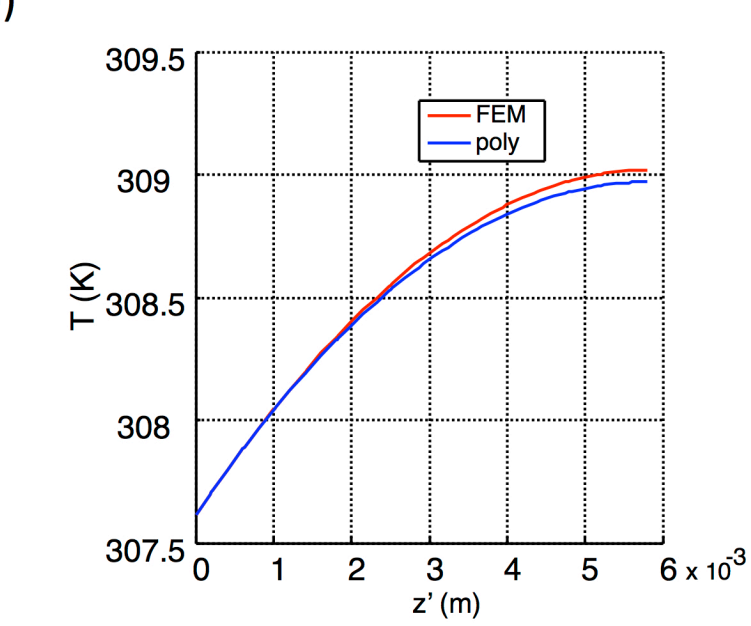

Figure 5: a) Steady state temperature distribution on the sample surface estimated by the thermal FEM model when the ambient temperature is $23^{\circ} \mathrm{C}$ and the temperature of the water circulating in the hole is $T_{\text {water }}=60$ ${ }^{\circ} \mathrm{C}$. b) Temperature profiles along the thickness direction, in point E, computed with the FEM model (red) and approximated by the parabolic model (blue).

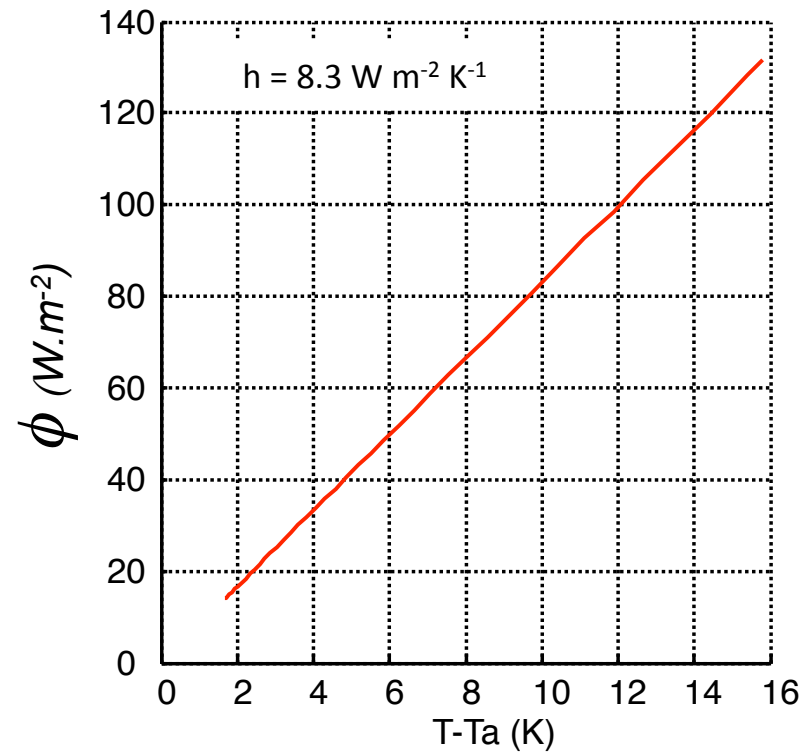

Figure 6: Variations in the two quantities described by equations (7) and (8), computed from simulation data. The slope of this linear curve allows identification of the convection exchange coefficient introduced in the model. 


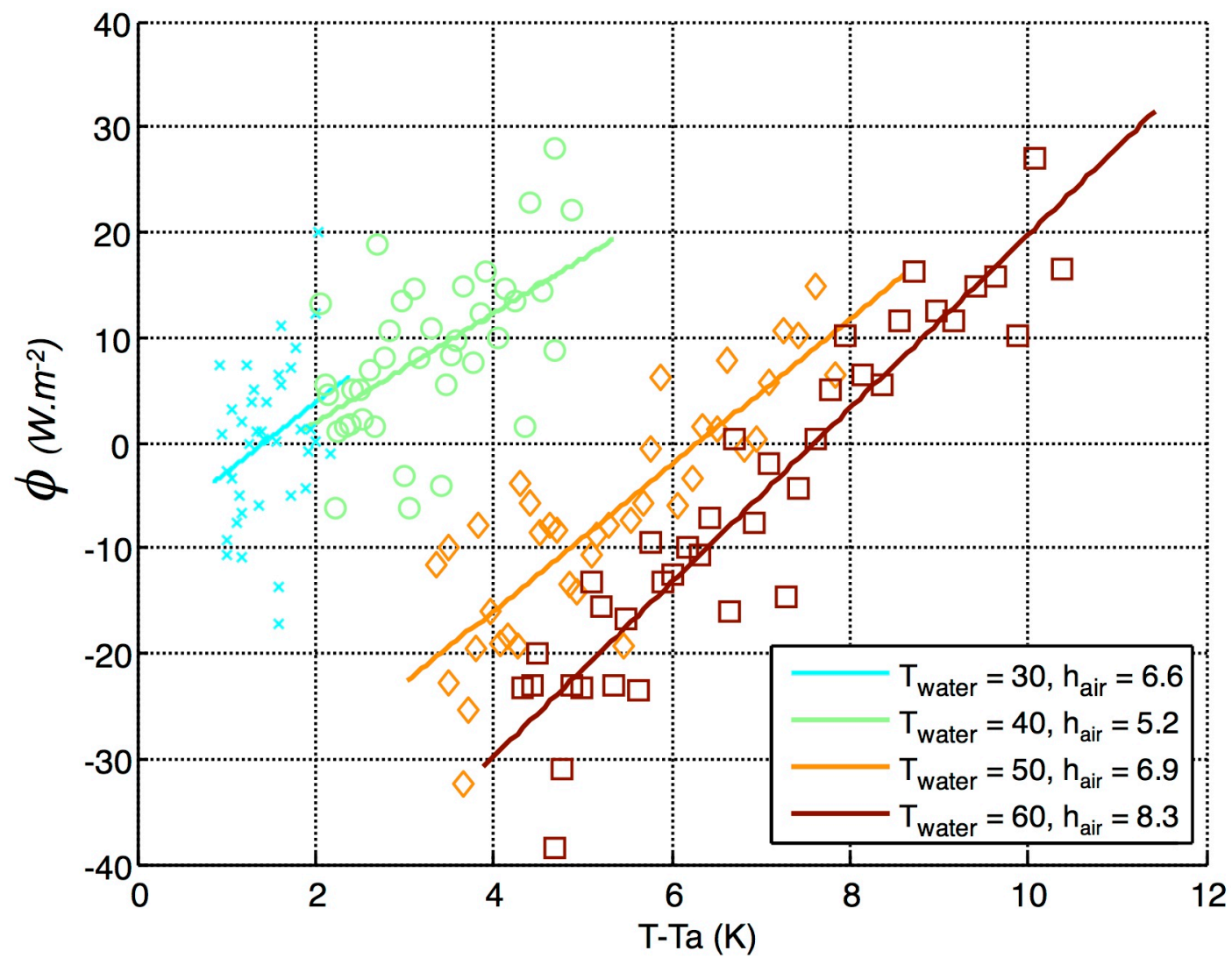

Figure 7 : Linear regression used to estimate the convection coefficients $\mathrm{h}$ (expressed in $\mathrm{W} \mathrm{m}^{-2} \mathrm{~K}^{-1}$ ) associated with the four loading states (water temperature ranging from $30^{\circ} \mathrm{C}$ to $60{ }^{\circ} \mathrm{C}$ )

a)

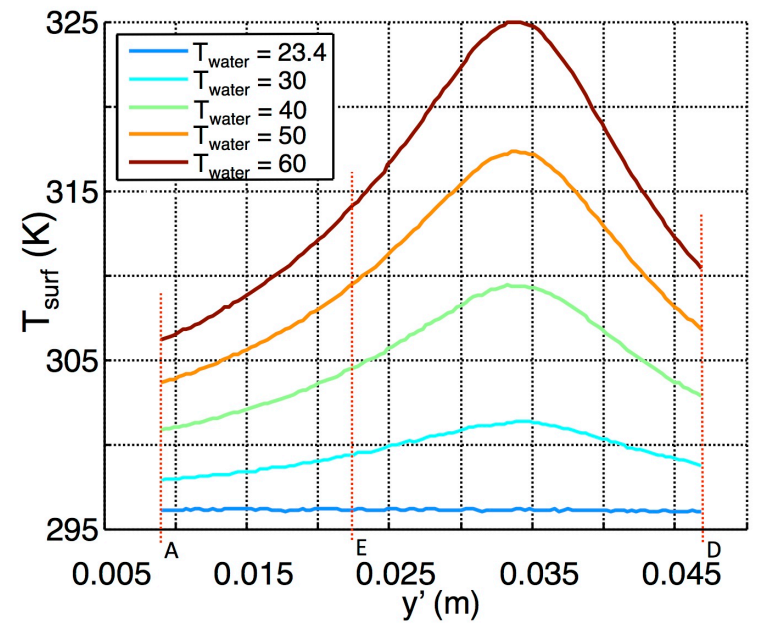

b)

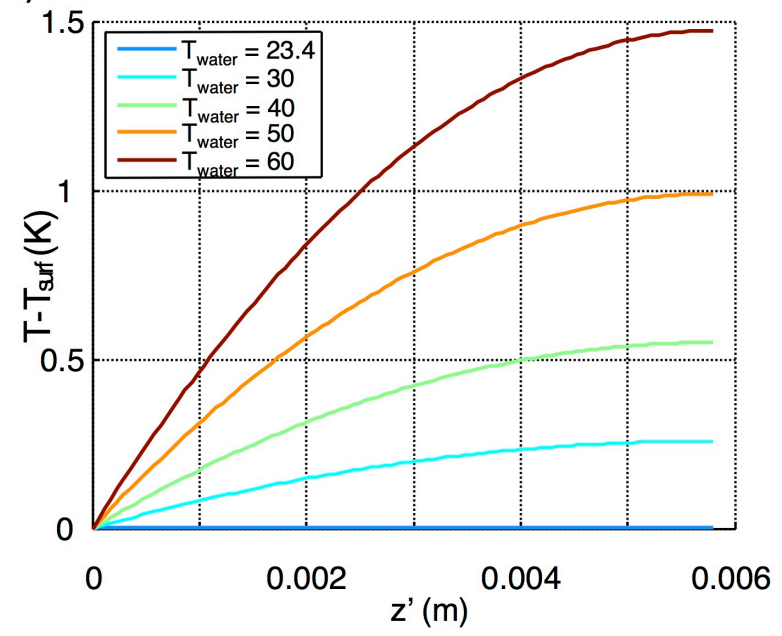

Figure 8 : a) Thermal profiles, along the AD line, measured at the surface during the reference state (ambient temperature $\mathrm{T}_{\mathrm{a}}$ at $23,4^{\circ} \mathrm{C}$ ) and during the four steady loading states (water temperature ranging from $30^{\circ} \mathrm{C}$ to $60^{\circ} \mathrm{C}$ ). b) Temperature variation profiles along the thickness direction, at point $\mathrm{E}$, for the four loading states, estimated with the parabolic thermal model and with the temperature measurement at point $\mathrm{E}$. 


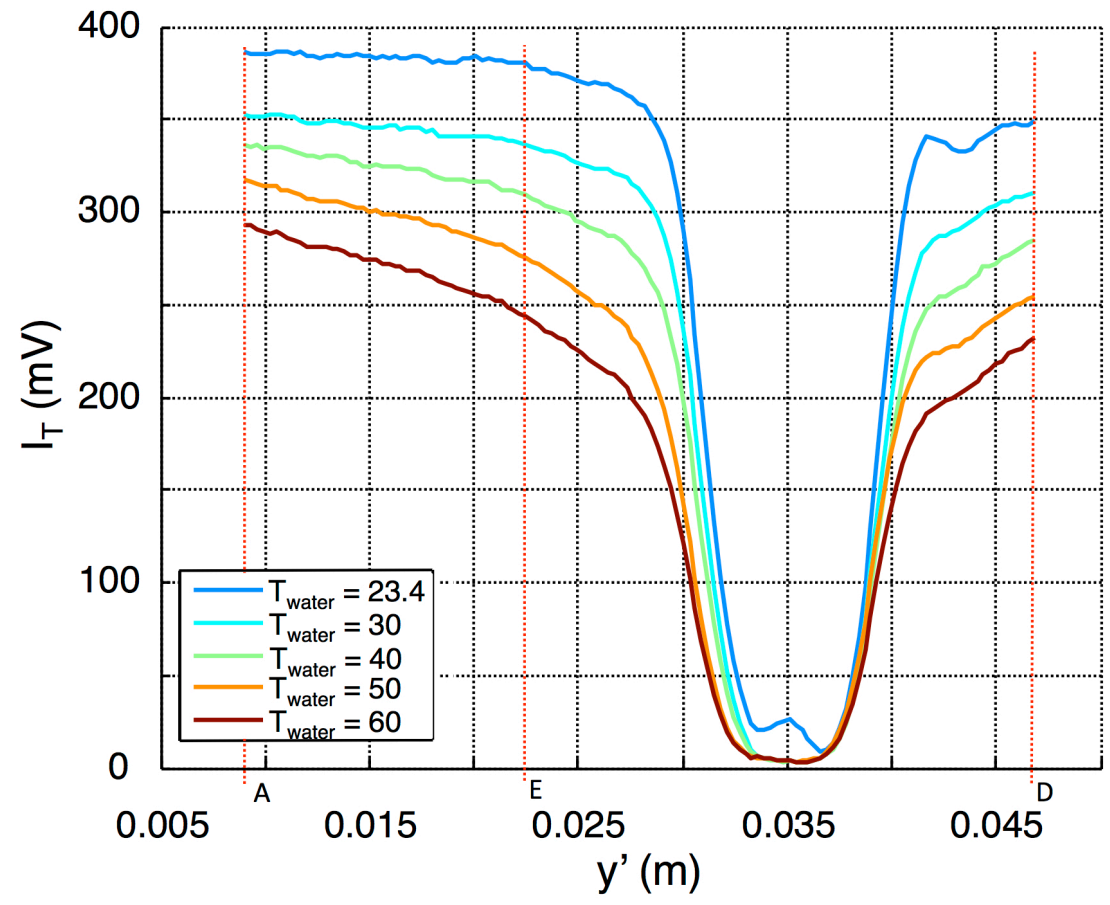

Figure 9: Transmitted THz profiles ( $\mathrm{mV}$ ), along the AD line, measured for the reference and the four loading states (water temperature ranging from $30^{\circ} \mathrm{C}$ to $60^{\circ} \mathrm{C}$ ).

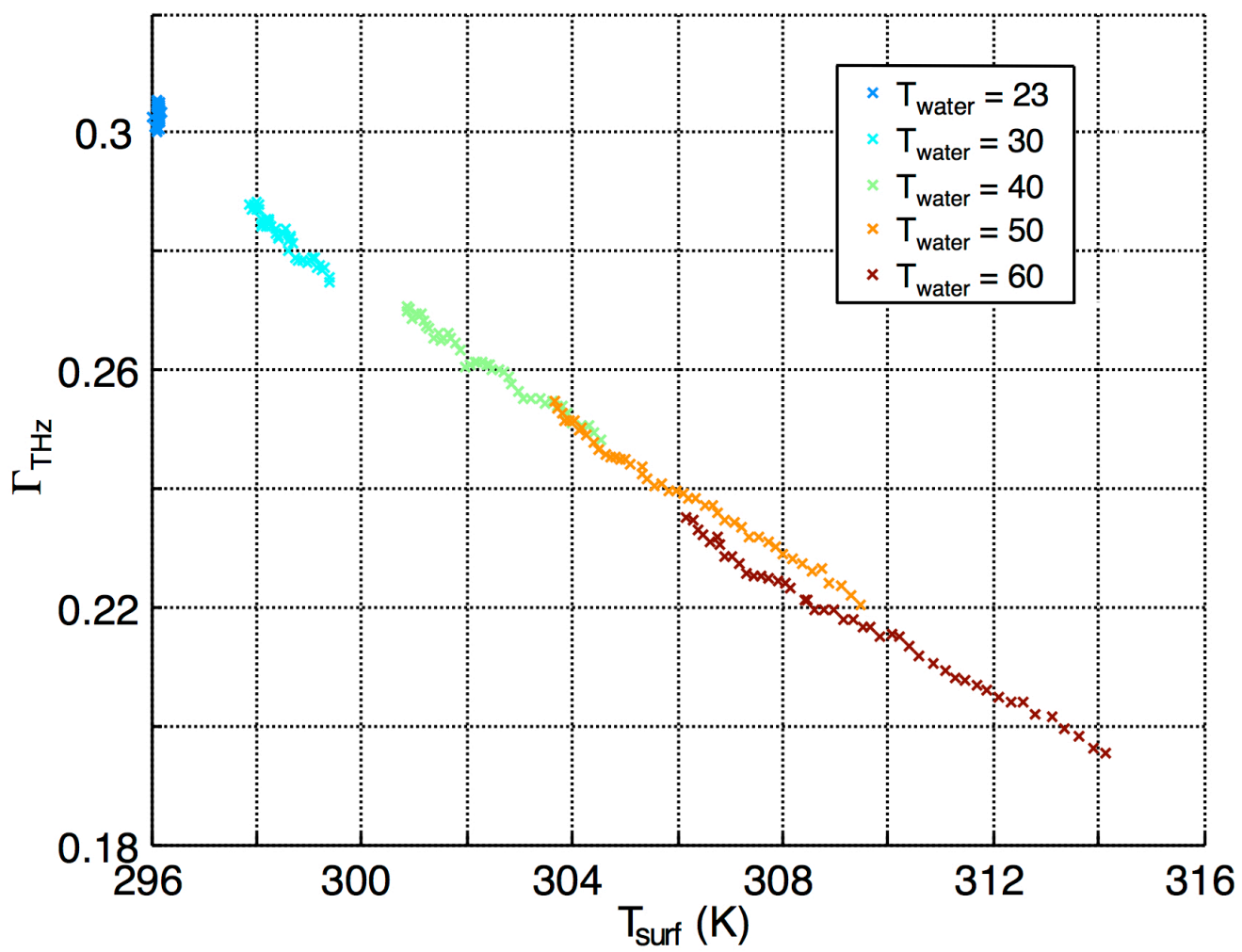

Figure 10 : Correspondence between the transmitted $\mathrm{THz}$ radiation and the surface temperature for all points located on the AE profile indicated in Figure 2, related to the four loading states (water temperature ranging from $30^{\circ} \mathrm{C}$ to $60^{\circ} \mathrm{C}$ ). 


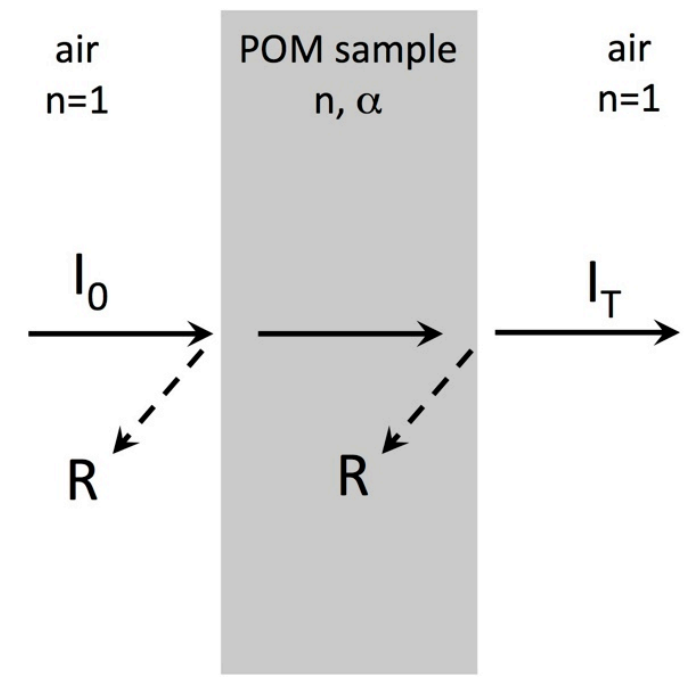

Figure 11: A simplified model for interactions between THz radiation and the POM sample.

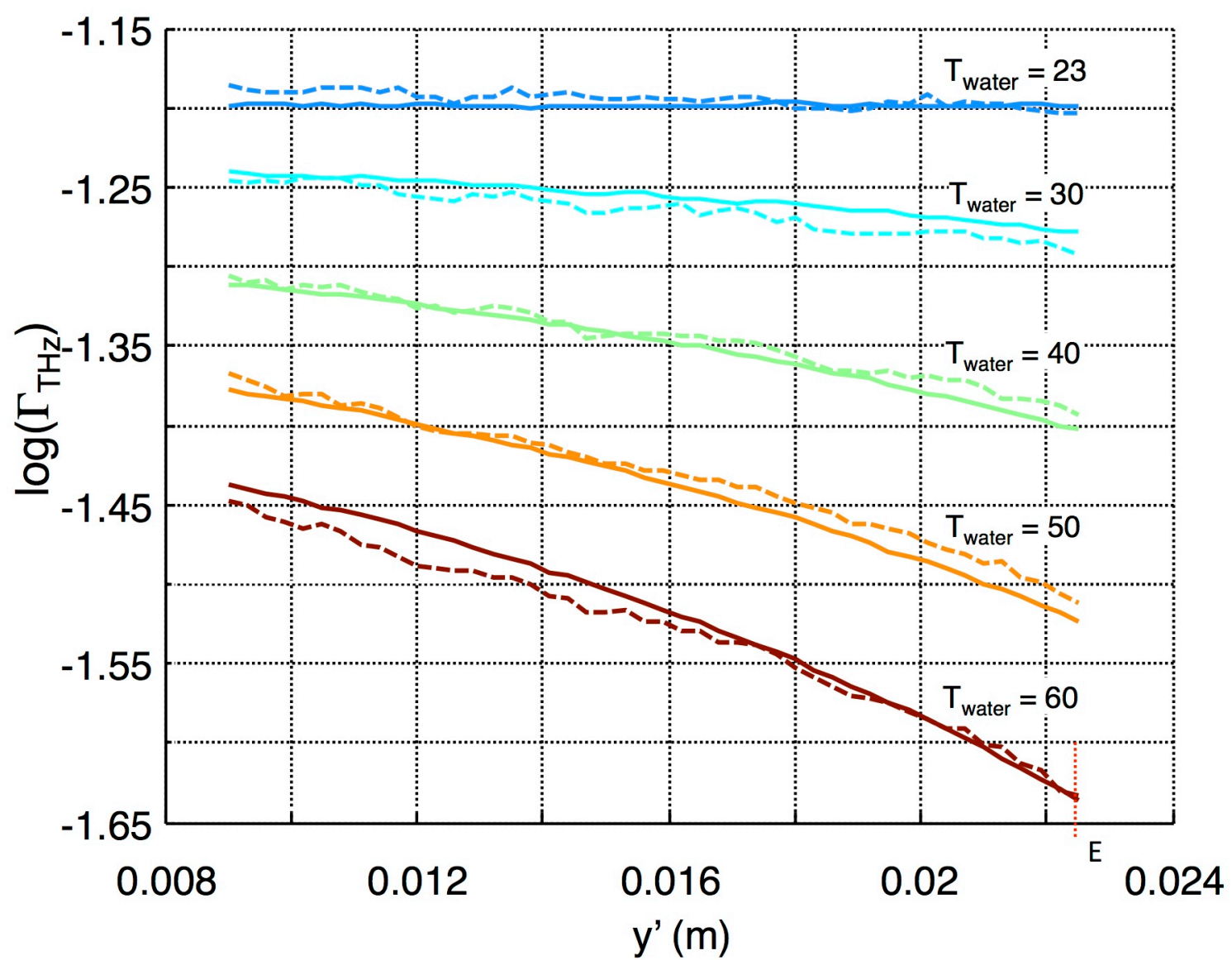

Figure 12: Variations in the transmission coefficient in the radial direction $y$ for all of the applied water temperatures $\boldsymbol{T}_{\text {water }}\left(\mathrm{in}^{\circ} \mathrm{C}\right)$. The experimental THz profiles are plotted with a dashed line and the "model" with a continuous line. 


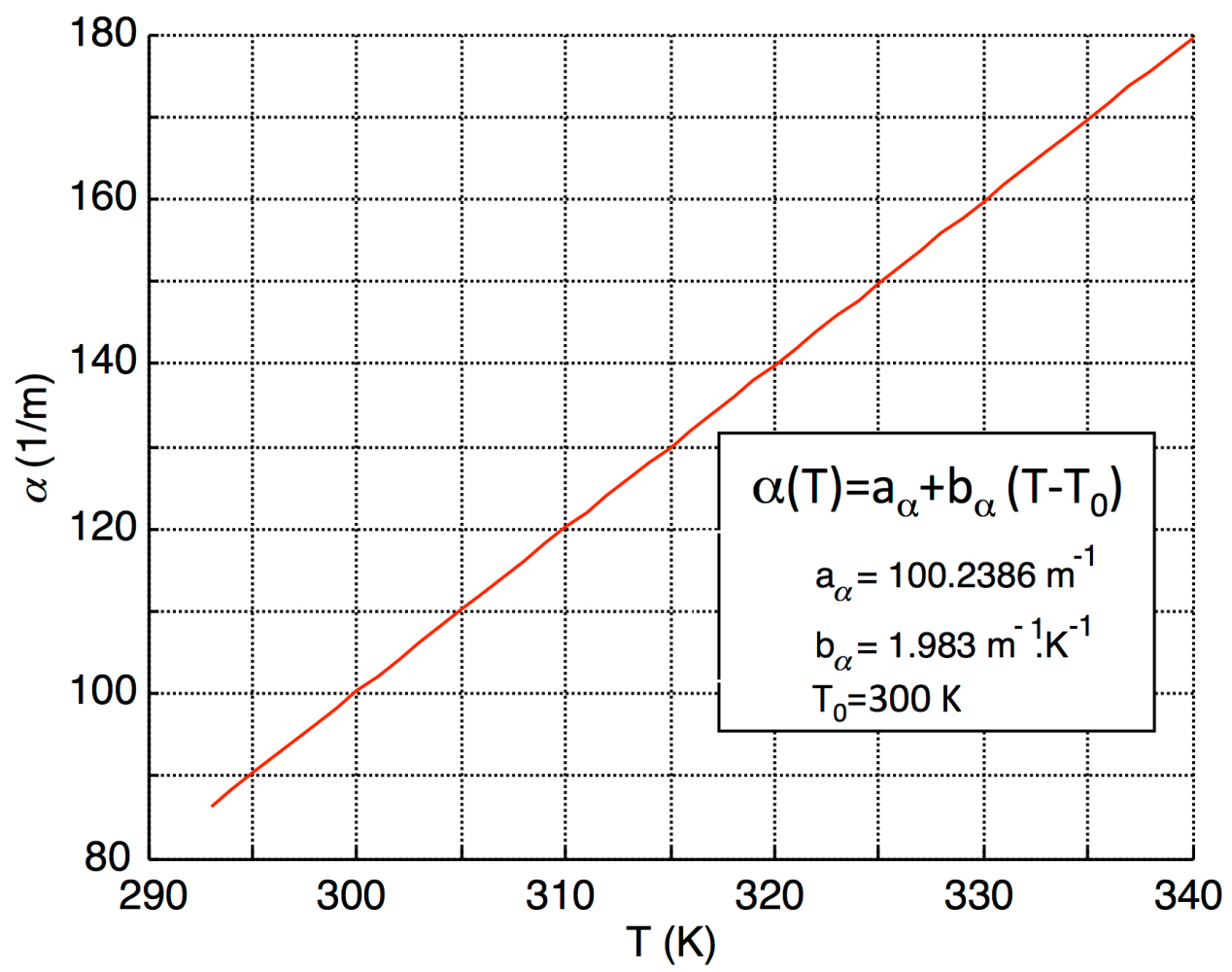

Figure 13: Variations in the absorption coefficient with temperature (eq. 12) for the POM sample identified from the experimental observations and minimization of the cost function (Eq. 15). 